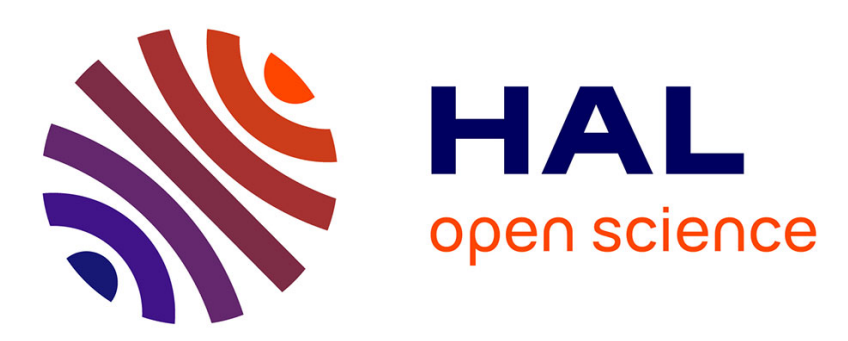

\title{
Impact of intragranular microstructure development on ductility limits of multiphase steels
}

Gérald Franz, Farid Abed-Meraim, Tarak Ben Zineb, Xavier Lemoine, Marcel Berveiller

\section{- To cite this version:}

Gérald Franz, Farid Abed-Meraim, Tarak Ben Zineb, Xavier Lemoine, Marcel Berveiller. Impact of intragranular microstructure development on ductility limits of multiphase steels. Materials Science and Engineering A- Structural Materials Properties Microstructure and Processing, 2011, 528 (10-11), pp.3777-3785. 10.1016/j.msea.2011.01.042 . hal-01203311

\section{HAL Id: hal-01203311 \\ https://hal.science/hal-01203311}

Submitted on 22 Sep 2015

HAL is a multi-disciplinary open access archive for the deposit and dissemination of scientific research documents, whether they are published or not. The documents may come from teaching and research institutions in France or abroad, or from public or private research centers.
L'archive ouverte pluridisciplinaire HAL, est destinée au dépôt et à la diffusion de documents scientifiques de niveau recherche, publiés ou non, émanant des établissements d'enseignement et de recherche français ou étrangers, des laboratoires publics ou privés. 


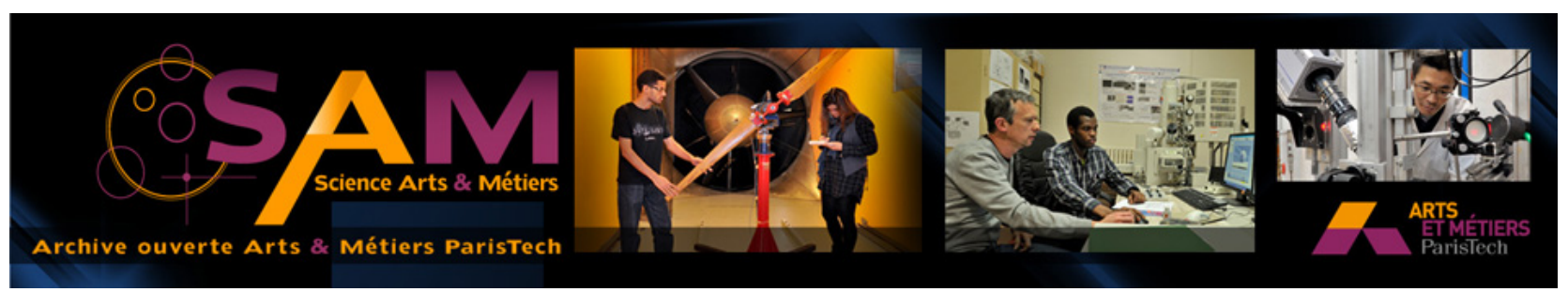

\section{Science Arts \& Métiers (SAM)}

is an open access repository that collects the work of Arts et Métiers ParisTech researchers and makes it freely available over the web where possible.

This is an author-deposited version published in: http://sam.ensam.eu

Handle ID: .http://hdl.handle.net/10985/10107

\section{To cite this version :}

Gérald FRANZ, Farid ABED-MERAIM, Tarak BEN ZINEB, Xavier LEMOINE, Marcel BERVEILLER - Impact of intragranular microstructure development on ductility limits of multiphase steels - Materials science and engineering A-Structural materials properties microstructure and processing - Vol. 528, n¹0-11, p.3777-3785 - 2011 


\title{
Impact of intragranular microstructure development on ductility limits of multiphase steels
}

\author{
Gérald Franz $^{\mathrm{a}}$, Farid Abed-Meraim ${ }^{\mathrm{b}, *}$, Tarak Ben Zineb ${ }^{\mathrm{c}}$, Xavier Lemoine ${ }^{\mathrm{d}, \mathrm{b}}$, Marcel Berveiller $^{\mathrm{b}}$ \\ ${ }^{a}$ LTI, EA 3899 - IUT Amiens, Avenue des Facultés - Le Bailly, 80025 Amiens Cedex 1, France \\ b LEM3, UMR CNRS 7239, Arts et Métiers ParisTech, 4 rue Augustin Fresnel, 57078 Metz Cedex 3, France \\ ${ }^{c}$ LEMTA, UMR CNRS 7563, Nancy University, 2 rue Jean Lamour, 54500 Vandœuvre-lès-Nancy, France \\ d ArcelorMittal Global RED, Voie Romaine, BP 30320, 57283 Maizières-lès-Metz Cedex, France
}

Keywords:

Micromechanics

Crystal plasticity

Self-consistent scale-transition

Intragranular substructure

Ductility

Plastic instability

\begin{abstract}
A B S T R A C T
In this paper, the effects of microstructure and deformation mechanisms on the ductility of multiphase steels are investigated. To this end, a formability criterion based on loss of ellipticity of the boundary value problem is coupled with an advanced multiscale model accounting for intragranular microstructure development and evolution. The spatially heterogeneous distribution of dislocations inside the grain is represented by three types of local dislocation densities. The resulting large strain elastic-plastic single crystal constitutive law (based on crystal plasticity) is incorporated into a self-consistent scale-transition scheme. The present contribution focuses on the relationship between the intragranular microstructure of B.C.C. steels and their ductility. The model allows interesting comparisons in terms of formability limits for different dislocation networks, during monotonic loading tests applied to polycrystalline aggregates.
\end{abstract}

\section{Introduction}

The development of relevant constitutive models that are welladapted to sheet metal forming simulations requires an accurate description of the most important sources of anisotropy, e.g., plastic slip processes, intragranular substructure changes and texture development.

During plastic deformation of thin metallic sheets, strain-path changes often occur in the material, resulting in macroscopic effects. These softening/hardening effects need to be properly predicted, because they can significantly influence the strain distribution and may lead to flow localization and material failure. These effects are thought to originate during the evolution of intragranular microstructure. This implies that an accurate description of the dislocation patterning associated with monotonic and/or complex strain-paths is a prerequisite for the formulation of reliable constitutive models.

For the past 20 years, a number of micromechanics-motivated multiscale models have been proposed with the aim of providing descriptions of the multiple sources of plastic anisotropy at their appropriate scales. Among these, the most advanced mod-

\footnotetext{
* Corresponding author. Tel.: +33 3873754 79; fax: +33 387375470

E-mail address: farid.abed-meraim@ensam.eu (F. Abed-Meraim).
}

els are those that attempt to account for the effects of dislocation heterogeneities on the macroscopic behavior of metallic materials.

In deformed material, the dislocations are heterogeneously distributed, with regions of high local dislocation density (called dense dislocation walls) alternating with regions of low local dislocation density (called dislocation cells). This particular dislocation organization results in a significant contrast in terms of the distribution of internal stresses, which are high in dislocation walls and low in dislocation cells. According to these observations, Mughrabi [1] was the first to assimilate the intragranular microstructure to a twophase composite description consisting of dislocation walls with high local dislocation density (hard phase) that are separated by regions with low local dislocation density (soft phase). Based on Mughrabi's pioneering contribution, Muller et al. [2], Lemoine et al. [3] and Langlois and Berveiller [4] proposed multiscale descriptions that take dislocation distribution morphology into account. Because the development of dislocation distributions during plastic deformation takes place at the mesoscopic scale, Peeters et al. [5,6] developed a new multiscale model that combines a micro-macro approach (using a full-constraints Taylor model [7]) with mesoscopic modeling. They showed that due to the specific properties of the dislocation walls with respect to polarity and latent hardening, the evolution of the dislocation substructure can be accurately described. 
The main objective of the present paper is to establish relationships between the heterogeneous arrangement of dislocations and the mechanical properties of metallic materials. More specifically, the focus is restricted here to the effect of microstructural mechanisms on material ductility. It is believed that a better understanding of these linkages will provide a useful tool that can be used to design new materials with enhanced properties, particularly in terms of their formability. Note that ductility is used here to mean formability, and these two concepts will be used interchangeably throughout the paper. For the above-mentioned purpose, a material instability criterion has been coupled with a crystal plasticity-based model that includes an accurate description of the heterogeneous dislocation distribution and which has been incorporated into a self-consistent scale-transition scheme. This multiscale model has been previously developed by the authors and recently presented in Franz et al. [8]. Its ability to describe the evolution of the intragranular heterogeneous dislocation distribution and to accurately predict the macroscopic behavior of single-phase polycrystalline steels during monotonic and sequential loading paths has been shown.

The paper is organized as follows. Section 2 briefly introduces the single crystal behavior model used (mesoscopic scale); a complete description is given in Franz et al. [9]. Also, because modeling at the microscale (i.e., the evolution of intragranular microstructure) has already been detailed in [8], only the main equations, essential to the current contribution are summarized through Section 3. In the same way, Sections 4 and 5 give, respectively, a short outline of the self-consistent scale-transition scheme and the plastic instability criterion adopted; the reader may refer to [9] for a comprehensive description. The main results are presented in Section 6 in terms of qualitative strain localization analyses for single-phase steels, where the impact of intragranular substructure development is investigated in detail for a 1000 -grain polycrystalline aggregate similar to the ferritic single-phase steel IF-Ti, for which the material parameters were identified in [8]. Finally, some concluding remarks are drawn in Section 7.

\section{Single crystal behavior modeling-mesoscopic scale}

Following the pioneering contributions [10-14], the elastic-plastic single crystal constitutive law modeled within the large strain framework is summarized in this section; the full details are available in [9]. The assumptions below are adopted:

- Plastic strain is assumed to be only due to crystallographic slip; no other inelastic strain mechanisms (e.g., twinning, phase transformation) are considered in this study.

- The single crystal constitutive law is valid for both B.C.C. and F.C.C. materials. However, because modeling at the microscale is based here on experimental observations of B.C.C. metals, application of this model is restricted to these metals, with 24 slip systems given by the two families <1 11>(110) and < $111>\left(\begin{array}{lll}1 & 12\end{array}\right)$.

- The local elastic-plastic constitutive law is given by a fourthorder tangent modulus $\mathbf{l}$ relating the nominal stress rate tensor $\dot{\mathbf{n}}$ to the velocity gradient $\mathbf{g}=\partial \mathbf{v} / \partial \mathbf{x}$ as

$\dot{\mathbf{n}}=\mathbf{1}: \mathbf{g}$

\subsection{Kinematics of crystallographic slip and plasticity}

Within the general framework of crystal plasticity, the total strain rate $\mathbf{d}$ and rotation rate $\mathbf{w}$ of a crystalline lattice are obtained as the symmetric and skew-symmetric parts, respectively, of the velocity gradient $\mathbf{g}$ (i.e., $\mathbf{g}=\mathbf{d}+\mathbf{w}$ ). These can be further split into their elastic and plastic components, indicated by superscripts ${ }^{e}$ and ${ }^{p}$, respectively, and related to the slip rates $\dot{\gamma}^{g}$ of each active slip system $g$ by:

$\mathbf{d}^{p}=\mathbf{d}-\mathbf{d}^{e}=\sum_{g} \mathbf{R}^{g} \dot{\gamma}^{g}, \quad \mathbf{w}^{p}=\mathbf{w}-\mathbf{w}^{e}=\sum_{g} \mathbf{S}^{g} \dot{\gamma}^{g}$

where $\mathbf{R}^{g}$ and $\mathbf{S}^{g}$ are, respectively, the well-known symmetric and skew-symmetric parts of the Schmid tensor $\overrightarrow{\mathbf{m}}^{g} \otimes \overrightarrow{\mathbf{n}}^{g}$ for a given slip system $g\left(\overrightarrow{\mathbf{n}}^{g}\right.$ being normal to the crystallographic slip plane and $\overrightarrow{\mathbf{m}}^{g}$ parallel to the slip direction).

\subsection{Regularized Schmid law and slip system activity}

The plastic flow is governed by the Schmid law, i.e., slip can only occur when the resolved shear stress acting on the slip system $g$, defined as $\tau^{g}=\boldsymbol{\sigma}: \mathbf{R}^{g}, \boldsymbol{\sigma}$ being the Cauchy stress tensor, reaches the critical resolved shear stress $\tau_{c}^{g}$. For effective slip activity, an additional condition is required $\left(\dot{\tau}^{g}=\dot{\tau}_{c}^{g}\right)$, i.e., the rate of the resolved shear stress must equal that of the critical resolved shear stress.

Using the new approach proposed in [15], the slip rate is given by a regularization function $\dot{\gamma}^{g}=k^{g}\left(\tau^{g}, \tau_{c}^{g}, \dot{\tau}^{g}\right) \dot{\tau}^{g}$. This method circumvents both the indeterminacy issue in selecting active slip systems and the associated lengthy combinatory analyses.

\subsection{Single crystal tangent modulus}

The local incremental elastic-plastic constitutive law is given by Eq. (1), in which the nominal stress rate $\dot{\mathbf{n}}$ is related to the Cauchy stress by

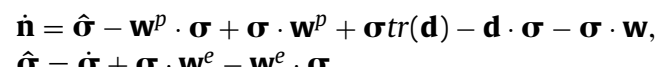

where $\hat{\boldsymbol{\sigma}}$, an objective derivative, denotes the lattice co-rotational derivative of the Cauchy stress tensor. Then, the local elastic-plastic tangent modulus is obtained as

$$
\begin{aligned}
l_{i j k l}= & {\left[C_{i j k l}-\frac{1}{2}\left(\delta_{i k} \sigma_{l j}+\delta_{i l} \sigma_{k j}\right)+\frac{1}{2}\left(\sigma_{i k} \delta_{l j}-\sigma_{i l} \delta_{j k}\right)\right] } \\
& -\left[\left(C_{i j p q} R_{p q}^{g}+S_{i p}^{g} \sigma_{p j}-\sigma_{i p} S_{p j}^{g}\right) M^{g h} R_{m n}^{\prime h}\left(C_{m n k l}-\sigma_{m n} \delta_{k l}\right)\right]
\end{aligned}
$$

where $C_{i j k l}$ and $\delta_{i k}$ denote, respectively, the components of the elasticity tensor and the second-order identity tensor, $R_{m n}^{\prime h}=k^{h} R_{m n}^{h}$, and $M^{g h}$ are the components of the $n_{g} \times n_{g}$ matrix obtained by inverting a matrix in which the $(h, g)$ th component is defined by $\left(\delta^{h g}+\mathbf{R}^{\prime h}: \mathbf{C}: \mathbf{R}^{\mathrm{g}}\right), \delta^{h g}$ being the components of the $n_{g} \times n_{g}$ identity matrix, with $n_{g}$ the current number of active slip systems.

\section{Modeling at the microscale: the evolution of intragranular microstructure}

This section gives the main equations of the microscopic model, which are based on experimental observations of B.C.C. crystals (Peeters et al. [5,6]). For more details, the reader may refer to the previous contribution by Franz et al. [8]. In this model, hardening is described through several dislocation densities and their evolution equations.

\subsection{Description of intragranular substructure}

Many TEM micrograph observations of deformed B.C.C. metals after monotonic and sequential loadings [16-20] show heterogeneous dislocation distributions and clearly distinguish two distinct dislocation density zones consisting of alternating straight planar regions of high local dislocation density (dislocation sheets) and low local dislocation density zones (cell interiors; see Fig. 1a, also reported in Franz et al. [8]). This intragranular substructure 


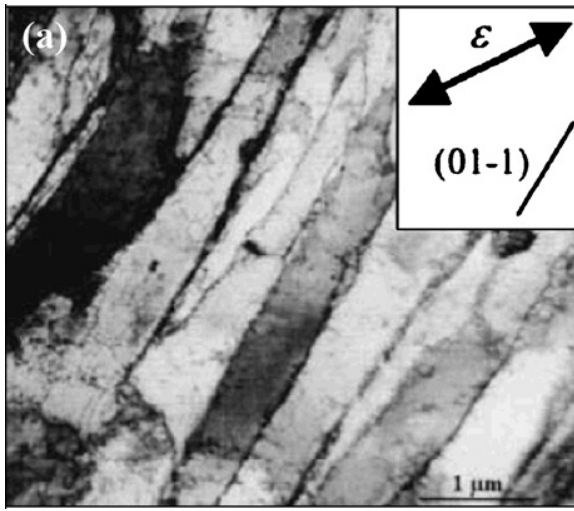

(b)

Dislocation wall $\rho^{(w d)}$

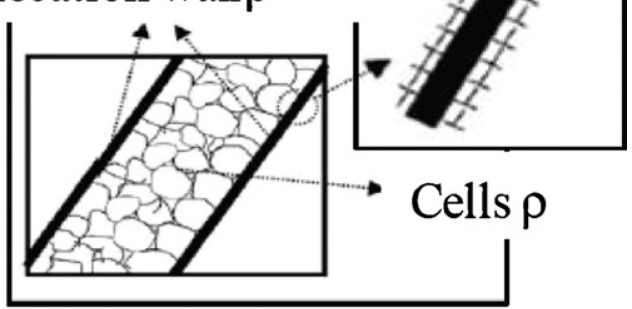

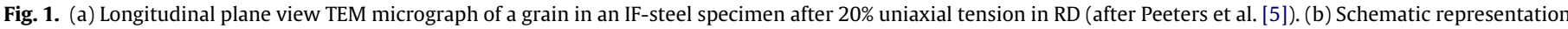
of the heterogeneous dislocation microstructure.

is described by three different types of dislocation densities introduced as internal variables in our model (see Fig. 1b, also shown in [8]).

The dislocations stored randomly inside cells are represented by a single local dislocation density $\rho$. Two other types of dislocation densities are associated with the dense dislocation walls: the density of immobile dislocations stored in the dislocation sheets $\rho^{w d}$, and the local, directionally movable or polarized dislocation density $\rho^{w p}$. This last one is assumed to have a sign that reproduces asymmetry in slip resistance.

\subsection{Formation of dense dislocation walls}

The dense dislocation walls are currently produced parallel to the crystallographic planes on which the slip activity is greatest $[20,21]$. The model will construct at most two families of dislocation sheets parallel to the $\left\{\begin{array}{lll}1 & 1 & 0\end{array}\right\}$ planes on which the highest and second highest slip activity rates occur, in agreement with experimental observations of B.C.C. crystals $[6,18,19]$, suggesting the presence of only one or two families of dense dislocation sheets parallel to $\left\{\begin{array}{lll}1 & 0\end{array}\right\}$ planes (see Fig. 2, also reported in Ref. [8]).

To account for the effect of the pre-existing microstructure and thus for the strain-path history of the material, the model will necessarily have to distinguish the evolution of currently existing dislocation walls from that of previously existing dislocation sheets.

\subsection{Evolution of the intensity of currently existing dislocation walls}

According to the earlier work of Kocks [22], the evolution of the local dislocation density $\rho^{w d}$ for each of the currently existing dislocation sheets can be expressed as

$\dot{\rho}_{i}^{w d}=\frac{1}{b}\left(I^{w d} \sqrt{\rho_{i}^{w d}}-R^{w d} \rho_{i}^{w d}\right) \dot{\Gamma}_{i}$

with $b$ representing the magnitude of the Burgers vector, $\dot{\Gamma}_{i}$ denoting the total slip rate on the crystallographic plane on which the $i$ th greatest slip activity occurs and $I^{w d}$ and $R^{w d}$ representing the immobilization and recovery parameters, respectively.

\subsection{Evolution of polarity assigned to currently existing dislocation walls}

As already detailed in [8], the evolution of the directionally movable dislocation density associated with currently existing walls can be expressed as follows

$\dot{\rho}_{i}^{w p}=\left(\operatorname{sign}\left(\phi_{i}^{w p}\right) I^{w p} \sqrt{\rho_{i}^{w d}+\left|\rho_{i}^{w p}\right|}-R^{w p} \rho_{i}^{w p}\right)\left|\phi_{i}^{w p}\right|$

where $\phi_{i}^{w p}=\sum_{s=1}^{n}\left(\dot{\gamma}^{s} / b\right) \mathbf{m}^{s} \cdot \mathbf{n}_{i}^{w}$ is the flux of the dislocations covering the boundaries of each existing generated wall $i$ from all of the slip systems non-coplanar to family $i$, and $n$ denotes the number of slip systems ( $n=24$ for B.C.C. crystals). The slip rate $\dot{\gamma}^{s}$ of slip system $s$ can be positive or negative; it thus integrates the different slip directions of a particular slip system. $\mathbf{m}^{s}$ is the unit vector assigned to the slip direction of system $s$, and $\mathbf{n}_{i}^{w}$ the unit vector perpendicular to the existing generated dense sheet $i . I^{w p}$ and $R^{w p}$ are, respectively, the immobilization and recovery parameters.

When the dislocation flux associated with a family of currently generated dense walls $i$ is reversed, e.g., during a reverse test, the polarity dislocations that have accumulated along the walls will
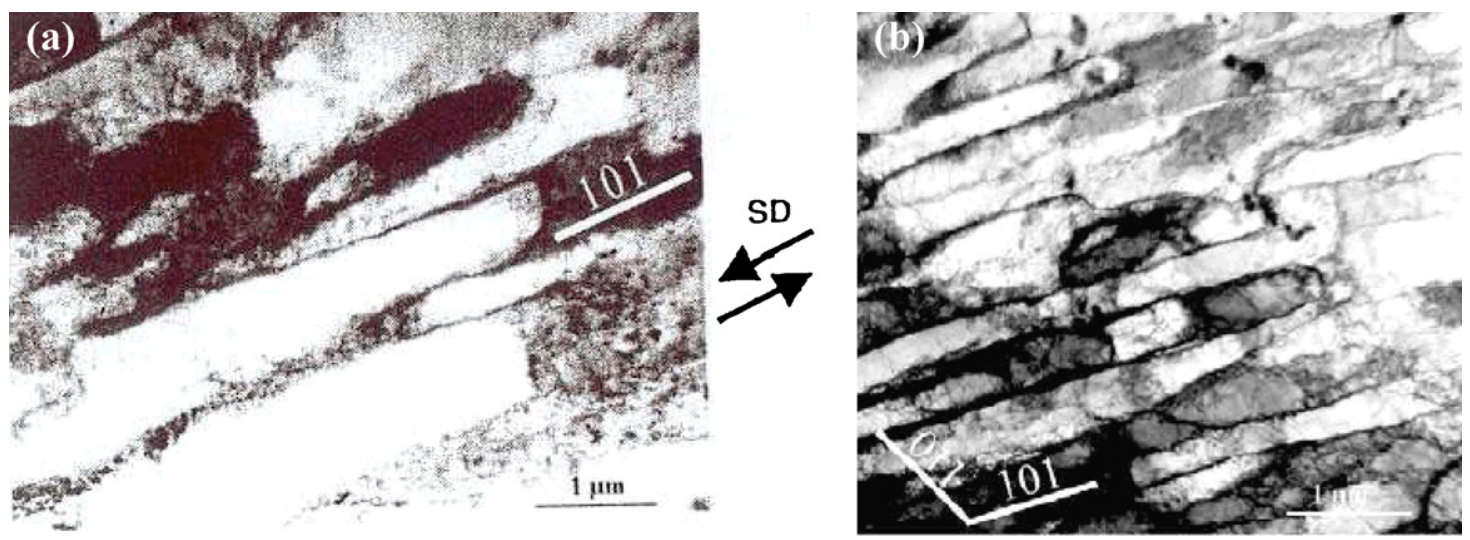

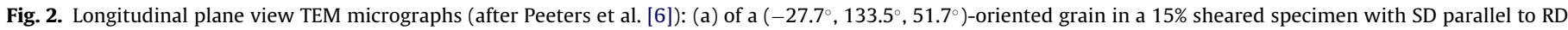
and SPN parallel to TD and (b) of a $\left(-41.6^{\circ}, 135.2^{\circ}, 38.7^{\circ}\right)$-oriented grain in a 30\% sheared specimen with SD parallel to RD and SPN parallel to TD. 
move away and be annihilated by dislocations of opposite sign:

$\dot{\rho}_{i}^{w p}=-R_{\text {rev }} \rho_{i}^{w p}\left|\phi_{i}^{w p}\right|$

with $R_{\text {rev }}$ the recovery parameter of polarized dislocations associated with the family $i$.

\subsection{Evolution of dislocation densities associated with former walls}

The activation of new slip systems may be caused by either a change in strain-path or a rotation of the grain towards a stable orientation. The associated mobile dislocations generate new families of dense walls corresponding to the current deformation mode and also disintegrate the former walls created by the previous slip activity, according to:

$\dot{\rho}_{i}^{w d}=-\frac{R_{n c g}}{b} \rho_{i}^{w d} \dot{\Gamma}_{n e w} \quad \dot{\rho}_{i}^{w p}=-\frac{R_{n c g}}{b} \rho_{i}^{w p} \dot{\Gamma}_{n e w}$

where $\dot{\Gamma}_{\text {new }}$ denotes the total slip rate on both of the crystallographic planes containing the highest slip activity and $R_{n c g}$ is a recovery parameter that characterizes the destruction of former dislocation walls.

\subsection{Formation and evolution of statistically stored dislocations in the cell interiors}

The statistically stored dislocations in the cell interiors are assumed to be responsible for the isotropic hardening. During a reverse test, the strain-path change leads to the activation of most of the slip systems that were active during the first strain-path, but in the opposite direction. The directionally movable dislocations responsible for the polarity of the dense walls will thus interact with dislocations of opposite sign in cells, leading to an increase in the annihilation rate of the randomly distributed dislocation network. To account for this phenomenon, an additional annihilation term is considered, which may be activated by a binary switch parameter $\Psi$, depending on whether there is reversal of the flux associated with a family of currently generated walls:

$\dot{\rho}=\frac{1}{b}\left\langle(I \sqrt{\rho}-R \rho) \sum_{s=1}^{n}\left|\dot{\gamma}^{s}\right|-\Psi R_{2} \frac{\rho^{\text {bausch }}}{2 \rho_{\text {sat }}^{w p}} \sum_{s=1}^{n}\left|\dot{\gamma}^{s}\right|\right\rangle$

where $\langle y\rangle=y$ if $y>0 ;\langle y>=0$ otherwise. $I$ and $R$ are, respectively, the immobilization and recovery parameters associated with the randomly distributed dislocation network, and $R_{2}$ a parameter that reflects the importance of the annihilation of the statistically stored dislocations in the cell interiors by the remobilized directionally movable dislocations associated with the dense dislocation sheets. The value of $\rho^{\text {bausch }}$ depends on the number of reversed fluxes.

\subsection{Isotropic hardening, latent hardening and polarity}

The critical resolved shear stress on each slip system $s$ includes the contributions of isotropic hardening, latent hardening and polarity, which are related to the three above-defined dislocation densities. The resulting critical resolved shear stress is then given by

$$
\begin{aligned}
\tau_{c}^{s}= & \tau_{c 0}^{s}+(1-f) \alpha \mu b \sqrt{\rho} \\
& +f \sum_{i=1}^{6} \alpha \mu b\left(\sqrt{\rho_{i}^{w d}}\left|\mathbf{m}^{s} \cdot \mathbf{n}_{i}^{w}\right|+\left\langle\sqrt{\left|\rho_{i}^{w p}\right|}\left(\mathbf{m}^{s} \cdot \mathbf{n}_{i}^{w}\right) \operatorname{sign}\left(\rho_{i}^{w p}\right)\right\rangle\right)
\end{aligned}
$$

where $f$ is the volume fraction of the dislocation sheets, $\alpha$ the dislocation interaction parameter, $\mu$ the shear modulus, and $\tau_{c 0}^{s}$ the initial critical resolved shear stress.

\section{Scale-transition scheme-polycrystalline behavior}

Once the single crystal behavior is described, including the modeling of the development of the intragranular microstructure, attention can be directed towards the overall polycrystalline aggregate. The derivation of polycrystal constitutive equations is based on a self-consistent scheme. Only the main lines of this approach are recounted here; the details of the entire scheme are developed in previous reports $[9,14,23,24]$.

The macroscopic behavior law linking the macroscopic nominal stress rate $\dot{\mathbf{N}}$ to the macroscopic velocity gradient $\mathbf{G}$ has the same form as for the single crystal (Eq. (1)):

$\dot{\mathbf{N}}=\mathbf{L}: \mathbf{G}$

The macroscopic velocity gradient and macroscopic nominal stress rate are given by the volume averages of their microscopic counterparts (see Ref. [24]):

$\mathbf{G}=\frac{1}{V} \int_{V} \mathbf{g}(\mathbf{x}) d v=\overline{\mathbf{g}(\mathbf{x})}, \quad \dot{\mathbf{N}}=\frac{1}{V} \int_{V} \dot{\mathbf{n}}(\mathbf{x}) d v=\overline{\dot{\mathbf{n}}(\mathbf{x})}$.

As is usual in averaging methods, the above macroscopic fields are related to their counterparts at the microscale by means of fourth-order concentration tensors $\mathbf{A}$ and $\mathbf{B}$ :

$\mathbf{g}(\mathbf{x})=\mathbf{A}(\mathbf{x}): \mathbf{G}, \quad \dot{\mathbf{n}}(\mathbf{x})=\mathbf{B}(\mathbf{x}): \dot{\mathbf{N}}$.

Combining the local behavior law Eq. (1) with Eqs. (10), (11) and (12), the macroscopic effective tangent modulus $\mathbf{L}$ can be written in a systematic manner:

$\mathbf{L}=\frac{1}{V} \int_{V} \mathbf{l}(\mathbf{x}): \mathbf{A}(\mathbf{x}) d v=\overline{\mathbf{l}(\mathbf{x}): \mathbf{A}(\mathbf{x})}$.

In [8], it has been shown that the proposed model is able to correctly reproduce the intragranular substructure for single crystals under different crystallographic orientations during various loading conditions. Moreover, the model reproduces the main features of the elastic-plastic behavior of single and dual-phase polycrystalline materials with reasonably good accuracy and consistency with experimental data.

\section{Plastic instability-modeling of formability limits}

Many contributions have been devoted to the modeling of plastic instability criteria. These range from engineering methods based

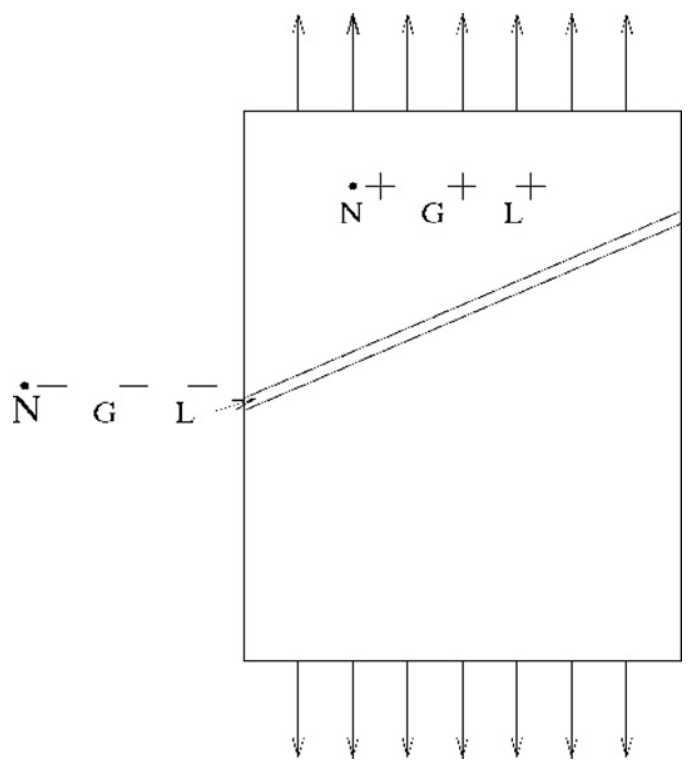

Fig. 3. Illustration of the localization of the deformation along a shear band [9]: mechanical fields outside the band are denoted by superscript ${ }^{+}$. 
Table 1

Material model parameters identified for IF-Ti steel [8].

\begin{tabular}{llllll}
\hline$I$ & $R[\mathrm{~m}]$ & $I^{w d}$ & $R^{w d}[\mathrm{~m}]$ & $I^{w p}$ & $R^{w p}[\mathrm{~m}]$ \\
\hline $4.5 \times 10^{-2}$ & $2.5 \times 10^{-9}$ & $1.8 \times 10^{-1}$ & $2 \times 10^{-9}$ & $4.5 \times 10^{-2}$ & $2 \times 10^{-9}$ \\
\hline$R_{\text {ncg }}[\mathrm{m}]$ & $R_{\text {rev }}[\mathrm{m}]$ & $R_{2}[\mathrm{~m}]$ & $f$ & $\tau_{\mathrm{c} 0}[110][\mathrm{MPa}]$ & $\tau_{\mathrm{c} 0}[112][\mathrm{MPa}]$ \\
\hline $5 \times 10^{-10}$ & $1 \times 10^{-9}$ & $1 \times 10^{-8}$ & 0.2 & 45 & 45 \\
\hline
\end{tabular}

on experimental or empirical observations to more theoretically sound approaches using either bifurcation or stability theories. Among the latter, the Rudnicki-Rice criterion [25,26] corresponds to a bifurcation associated with admissible jumps for strain and stress rates across a shear band (Fig. 3).

Because field equations have to be satisfied, and because the strain rate is discontinuous across the localization band, a kinematic condition for the strain rate jump must be verified. Also, the continuity of the stress rate vector has to be verified for the forces along the localization band. The reader may refer to Ref. [9] for more details.

Combining these conditions, a bifurcation criterion, which can be used for modeling the formability limit, is expressed as a function of the macroscopic tangent modulus:

$\operatorname{det}(\boldsymbol{v} \cdot \mathbf{L} \cdot \boldsymbol{v})=0$
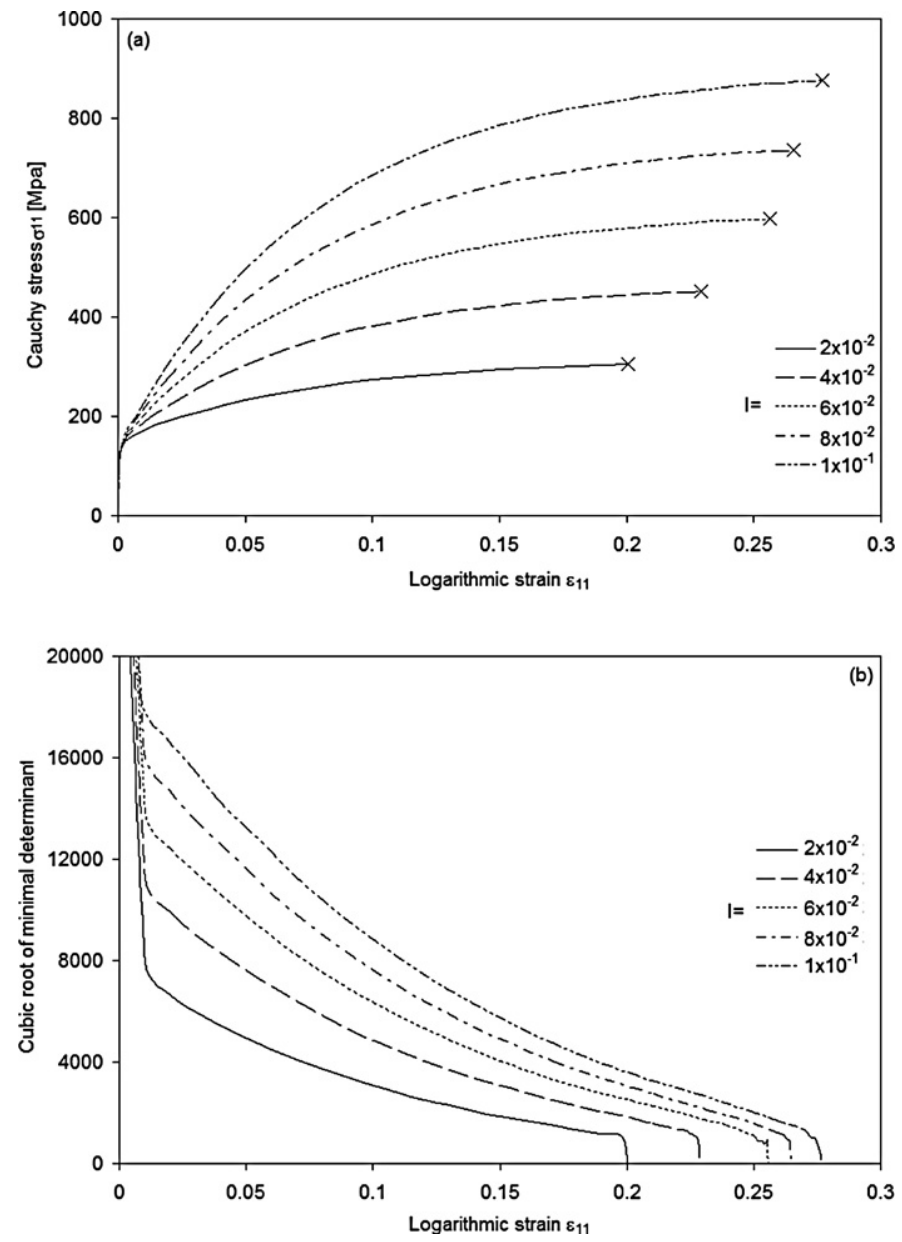

Fig. 4. Effect of the immobilization parameter $I$ (associated with the randomly distributed dislocation network) on the ductility limit of polycrystalline steel: (a) stress-strain behavior for plane strain tension. (b) Minimal determinant of the acoustic tensor over all orientations of the normal to the localization band.
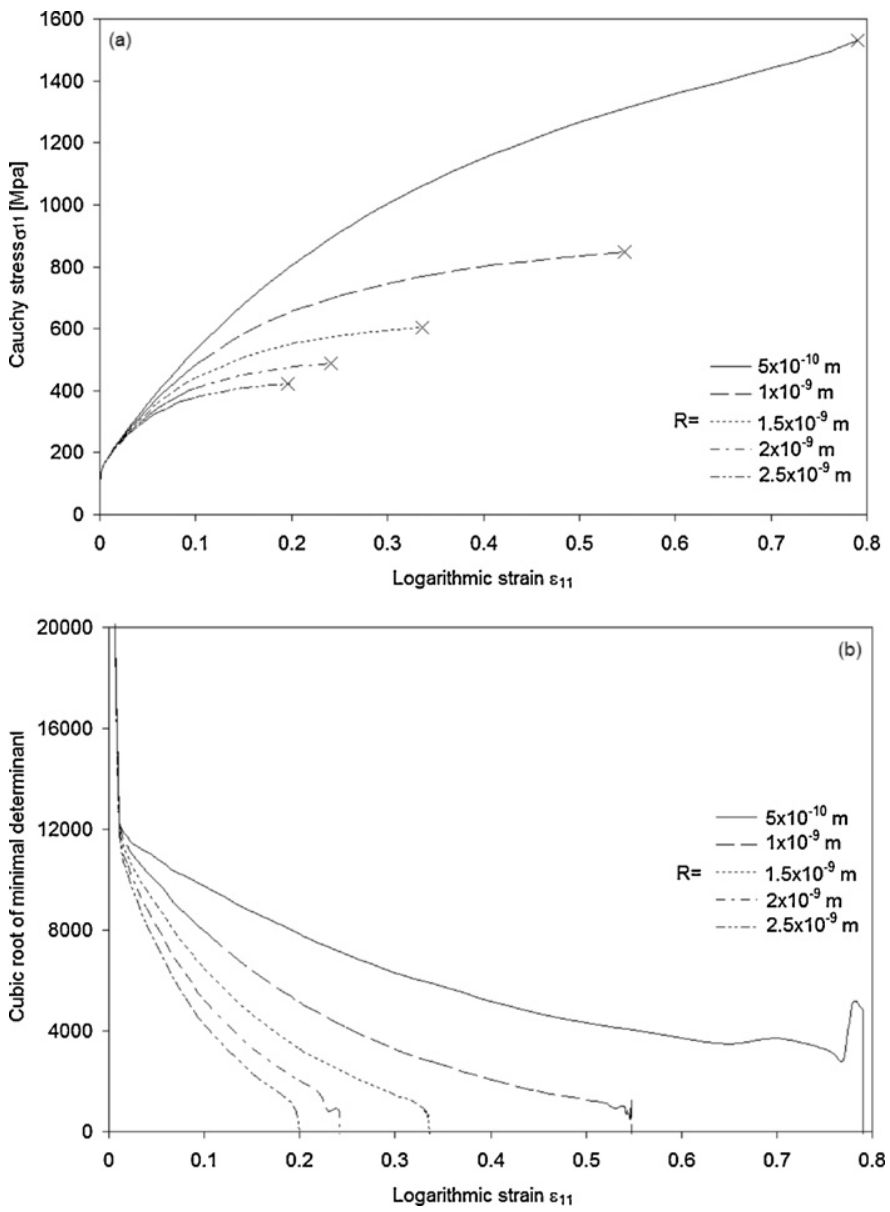

Fig. 5. Effect of the recovery parameter $R$ (associated with the randomly distributed dislocation network) on the ductility limit of polycrystalline steel: (a) stress-strain behavior for plane strain tension. (b) Minimal determinant of the acoustic tensor over all orientations of the normal to the localization band.

In the above eigenvalue problem, which corresponds to the singularity of the acoustic tensor, $\boldsymbol{v}$ is the unit vector normal to the shear band.

\section{Numerical results-strain localization analysis}

In previous contributions (see Franz et al. [9,27]), the above localization criterion has been applied to a simplified micromechanical model that does not account for intragranular microstructure development. Investigation of plastic instability using Rice's bifurcation criterion allowed us to determine Forming Limit Diagrams (FLDs) for single-phase and dual-phase steels. This FLD concept has proven to be useful for preventing defective parts in the context of sheet metal forming processes $[28,29]$.

In the present work, the above formability criterion is coupled with micromechanical modeling after enrichment of the elastic-plastic single crystal behavior law with an intragranular substructure description. The main focus is to establish relationships between microstructural properties (and their underlying physical mechanisms) and material ductility. Some of the motivation behind this is to provide a prediction tool that can be used to classify materials in terms of ductility. This tool could also be used to optimize material properties or to design new grades of steel with enhanced in-use mechanical properties.

In the following sections, the qualitative impact of microstructural mechanisms on ductility will be investigated. In this process, the effect on ductility of the model parameters, which are asso- 
Table 2

Subset of material parameters identified for IF-Ti steel corresponding to the partially modeled intragranular microstructure.

\begin{tabular}{llllll}
\hline$I$ & $R[\mathrm{~m}]$ & $I^{w d}$ & $R^{w d}[\mathrm{~m}]$ & $I^{w p}$ & $R^{w p}[\mathrm{~m}]$ \\
\hline $4.5 \times 10^{-2}$ & $2.5 \times 10^{-9}$ & 0 & 0 & 0 & 0 \\
& & & & & \\
\hline$R_{\text {ncg }}[\mathrm{m}]$ & $R_{\text {rev }}[\mathrm{m}]$ & $R_{2}[\mathrm{~m}]$ & $f$ & $\tau_{\mathrm{c} 0}[110][\mathrm{MPa}]$ & $\tau_{\mathrm{c} 0}[112][\mathrm{MPa}]$ \\
\hline 0 & 0 & 0 & 0 & 45 & 45
\end{tabular}

ciated with elementary physical mechanisms at the microscale, will be analyzed during monotonic loading tests. These parameters include the immobilization parameters $I, I^{w d}, I^{w p}$; the recovery parameters $R, R^{w d}, R^{w p}$; the initial critical resolved shear stress $\tau_{\mathrm{c} 0}$ and the volume fraction $f$ of the dislocation sheets. This analysis is conducted on a 1000-grain polycrystalline aggregate similar to the ferritic single-phase steel IF-Ti, for which the identified parameter values are reported in Table 1 (see Ref. [8] for more details on the identification procedure).

Note that for consistency reasons, the results are shown for plane strain tensile tests because the associated limit strain corresponds to the lowest point of the FLD, and this is a good indication of the overall forming limit and hence of the material ductility. For other monotonic loading tests (uniaxial tension and equibiaxial expansion), the results obtained show the same trends and could be given in the same way. Moreover, the influence of the remaining parameters (i.e., $R_{n c g}, R_{\text {rev }}$ and $R_{2}$ ) during monotonic tests is shown to be negligible, as they are specific to sequential loading
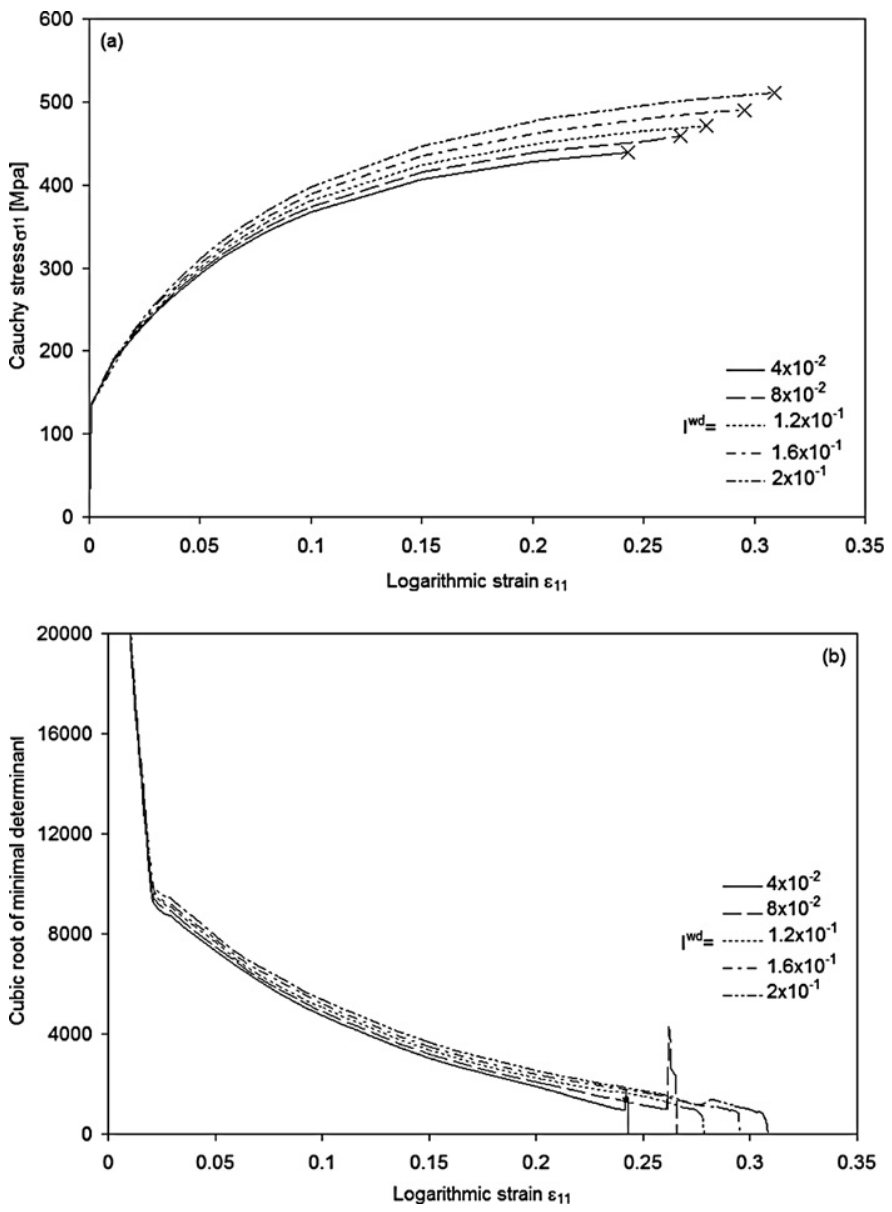

Fig. 6. Effect of the immobilization parameter $I^{w d}$ (associated with currently existing dislocation walls) on the ductility limit of polycrystalline steel: (a) stress-strain behavior for plane strain tension. (b) Minimal determinant of the acoustic tensor over all orientations of the normal to the localization band. tests. Consequently, only key parameters will be analyzed in what follows, and they will be progressively activated to separate their respective effects and to clearly identify the impact of each component associated with the microscopic modeling. Throughout these analyses, the subset of parameters (which is kept constant) is identified for IF-Ti steel using five different experimental tests [8], while the remaining parameters are varied to investigate their effects on ductility.

\subsection{Impact of the randomly distributed dislocation network}

In this first analysis, the internal substructure is taken with no particular organization, which means that the dislocations are distributed in a totally random way. To reproduce this assumed configuration, all of the values of the model parameters are set to zero, except for the immobilization parameter $I$ and the recovery parameter $R$. Thus, Figs. 4 and 5 are obtained by keeping all of the parameters of Table 2 constant while varying parameters $I$ and $R$, respectively.

The microscopic modeling uses Eq. (9) for the evolution of randomly distributed dislocations. Examination of this equation reveals that it contains two terms of opposite signs corresponding, respectively, to the storage and annihilation of dislocations in the cell interiors. The immobilization parameter I characterizes the number of dislocations that are going to be trapped inside cells. Larger values of this parameter induce more obstacles to slip and result in an increase in hardening that leads to enhanced ductility.
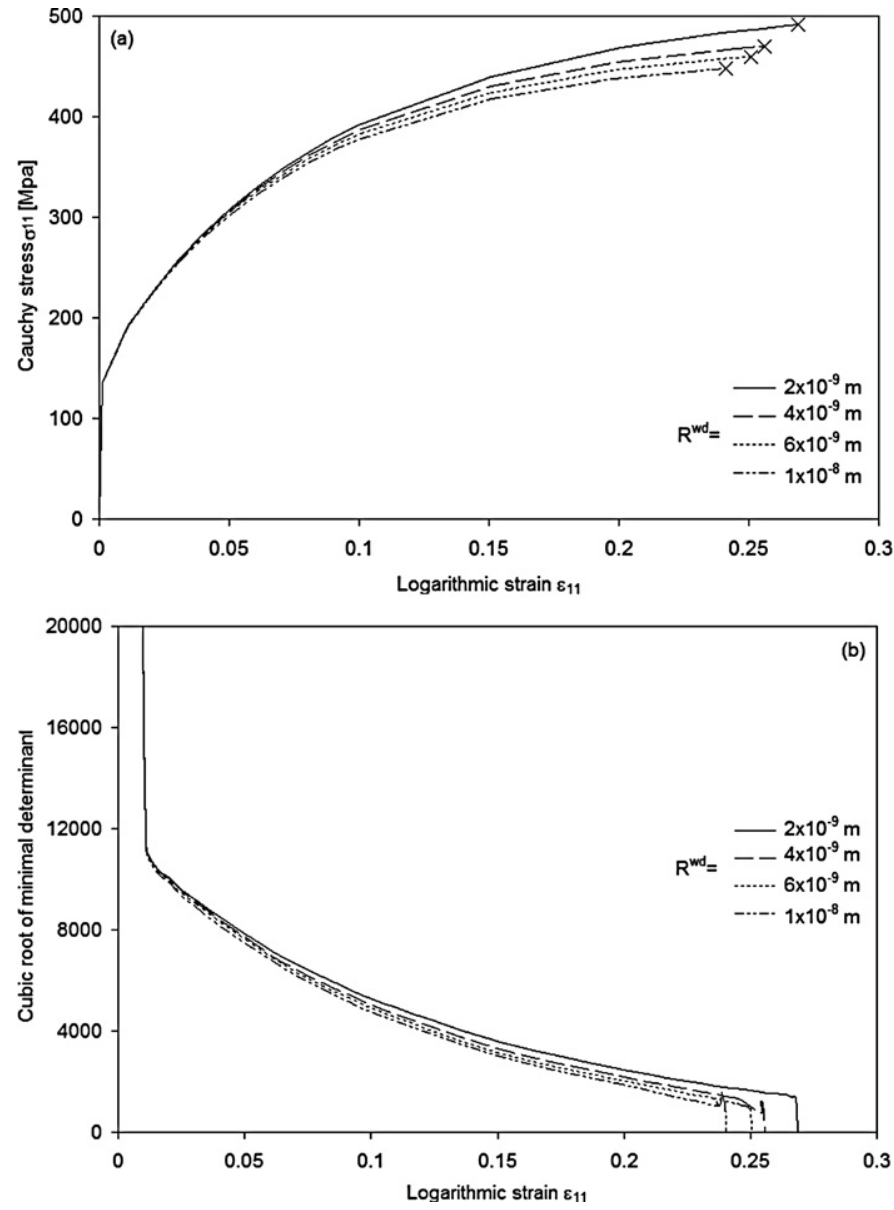

Fig. 7. Effect of the recovery parameter $R^{w d}$ (associated with currently existing dislocation walls) on the ductility limit of polycrystalline steel: (a) stress-strain behavior for plane strain tension. (b) Minimal determinant of the acoustic tensor over al orientations of the normal to the localization band. 
Table 3

Subset of material parameters identified for IF-Ti steel corresponding to the partially modeled intragranular microstructure.

\begin{tabular}{llllll}
\hline$I$ & $R[\mathrm{~m}]$ & $I^{w d}$ & $R^{w d}[\mathrm{~m}]$ & $I^{w p}$ & $R^{w p}[\mathrm{~m}]$ \\
\hline $4.5 \times 10^{-2}$ & $2.5 \times 10^{-9}$ & $1.8 \times 10^{-1}$ & $2 \times 10^{-9}$ & 0 & 0 \\
\hline$R_{n c g}[\mathrm{~m}]$ & $R_{\text {rev }}[\mathrm{m}]$ & $R_{2}[\mathrm{~m}]$ & $f$ & $\tau_{\mathrm{c} 0}[110][\mathrm{MPa}]$ & $\tau_{\mathrm{c} 0}[112][\mathrm{MPa}]$ \\
\hline 0 & 0 & 0 & 0.2 & 45 & 45 \\
\hline
\end{tabular}

This trend is clearly reproduced by the proposed model, as shown in Fig. 4. Note that in Fig. 4a, the end of the stress-strain curves (indicated by a cross) corresponds to the occurrence of strain localization. Fig. $4 \mathrm{~b}$ gives plots of the minimal value of the cubic root of the determinant of the acoustic tensor $(\operatorname{det}(\boldsymbol{v} \cdot \mathbf{L} \cdot \boldsymbol{v}))^{1 / 3}$ over all orientations of the normal $\boldsymbol{v}$ to the localization band versus the macroscopic logarithmic strain for various values of the immobilization parameter $I$.

In the same way, the importance of the annihilation of randomly distributed dislocations can be quantified by means of the recovery parameter $R$. Larger values of this parameter mean that more dislocations are going to disappear, making slip motion easier. Therefore, this softening effect due to dislocation annihilation contributes to the overall softening of the material, thus promoting early strain localization (see Fig. 5).
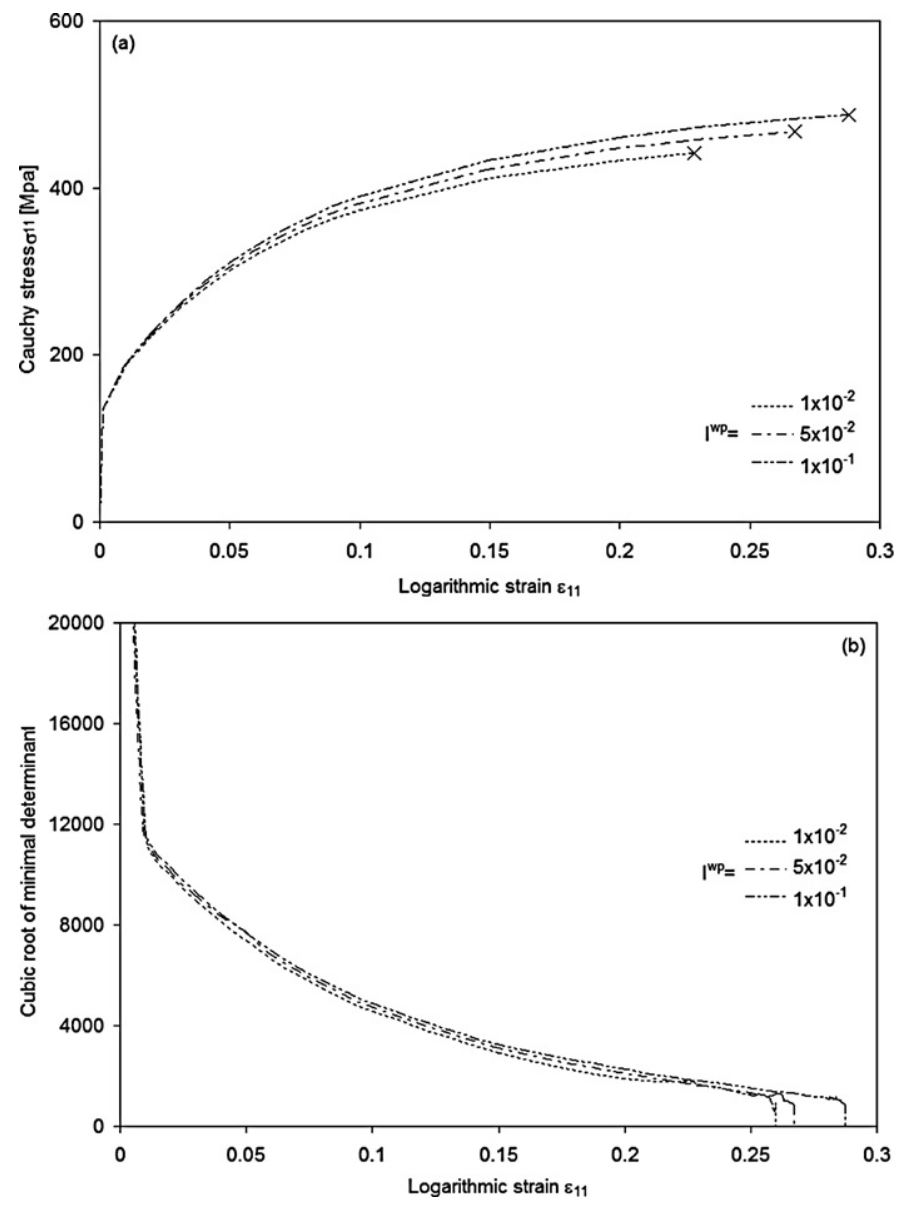

Fig. 8. Effect of the immobilization parameter $I^{w p}$ (associated with currently existing dislocation walls) on the ductility limit of polycrystalline steel: (a) stress-strain behavior for plane strain tension. (b) Minimal determinant of the acoustic tensor over all orientations of the normal to the localization band.
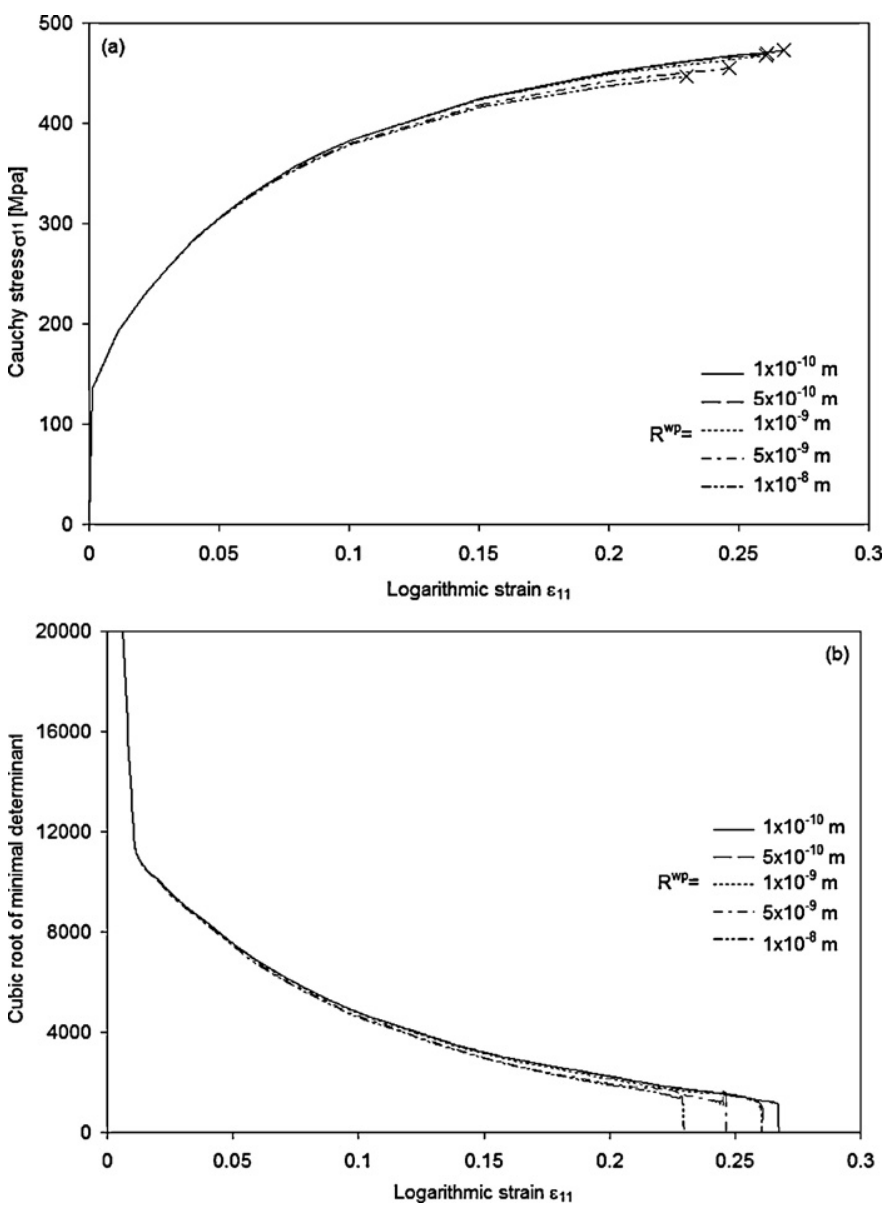

Fig. 9. Effect of the recovery parameter $R^{w p}$ (associated with currently existing dislocation walls) on the ductility limit of polycrystalline steel: (a) stress-strain behavior for plane strain tension. (b) Minimal determinant of the acoustic tensor over all orientations of the normal to the localization band.

\subsection{Impact of the dense dislocation sheets}

In this section, the intragranular substructure is assumed to present an organized dislocation network consisting of cell structure and dense dislocation sheets. In this context, the two parameters $I^{w d}$ and $R^{w d}$ are both activated. Figs. 6 and 7 are obtained by varying the values of parameters $I^{w d}$ and $R^{w d}$, respectively, while the remaining material parameters (reported in Table 3 ) are kept constant.

In terms of macroscopic hardening, $I^{w d}$ and $R^{w d}$ have the same influence as $I$ and $R$, respectively, as they convey the same mechanisms but for dislocations stored in the walls, as shown in Figs. $6 a$ and $7 a$.

According to Eq. (5), larger values of the immobilization parameter $I^{w d}$ produce dense dislocation walls with higher intensity, which seems to induce an increase in ductility, as shown in Fig. 6b. This is because the generation of dense dislocation sheets parallel to the crystallographic planes on which the slip activity is greatest means that fewer dislocations are likely to act as obstacles to the slippage of other dislocations.

On the other hand, the recovery parameter $R^{w d}$ is expected to exert an effect opposite to that of the immobilization parameter $I^{w d}$. This is well-verified in Fig. 7b, which shows that larger values of $R^{w d}$ produce a drop in ductility. 
Table 4

Subset of material parameters identified for IF-Ti steel corresponding to the partially modeled intragranular microstructure.

\begin{tabular}{llllll}
\hline$I$ & $R[\mathrm{~m}]$ & $I^{w d}$ & $R^{w d}[\mathrm{~m}]$ & $I^{w p}$ & $R^{w p}[\mathrm{~m}]$ \\
\hline $4.5 \times 10^{-2}$ & $2.5 \times 10^{-9}$ & $1.8 \times 10^{-1}$ & $2 \times 10^{-9}$ & $4.5 \times 10^{-2}$ & $2 \times 10^{-9}$ \\
& & & & \\
\hline$R_{\text {ncg }}[\mathrm{m}]$ & $R_{\text {rev }}[\mathrm{m}]$ & $R_{2}[\mathrm{~m}]$ & $f$ & $\tau_{\mathrm{c} 0}[110][\mathrm{MPa}]$ & $\tau_{\mathrm{c} 0}[112][\mathrm{MPa}]$ \\
\hline $5 \times 10^{-10}$ & 0 & 0 & 0.2 & 45 & 45 \\
\hline
\end{tabular}

\subsection{Impact of the polarized dislocations}

As previously modeled, the intragranular substructure here consists of cell structure and dense dislocation sheets; however, the dipolar character of dislocation walls is now taken into account with the additional activation of the two parameters $I^{w p}$ and $R^{w p}$ [see Eq. (6)]. The associated material parameter values are reported in Table 4 . By varying the values of $I^{w p}$ and $R^{w p}$, their respective effect on ductility is illustrated in Figs. 8 and 9.

Concerning material strength, variation of the material parameter $I^{w p}$ is expected to have the same consequences as varying the parameters $I$ and $I^{w d}$, whereas variation of $R^{w p}$ is expected to have the same consequences as varying $R$ and $R^{w d}$ This is clearly shown in Figs. 8a and 9a.

According to Eq.(6), larger values of the immobilization parameter $I^{w p}$ or smaller values of the recovery parameter $R^{w p}$ lead to more directionally movable dislocations accumulating along the dense
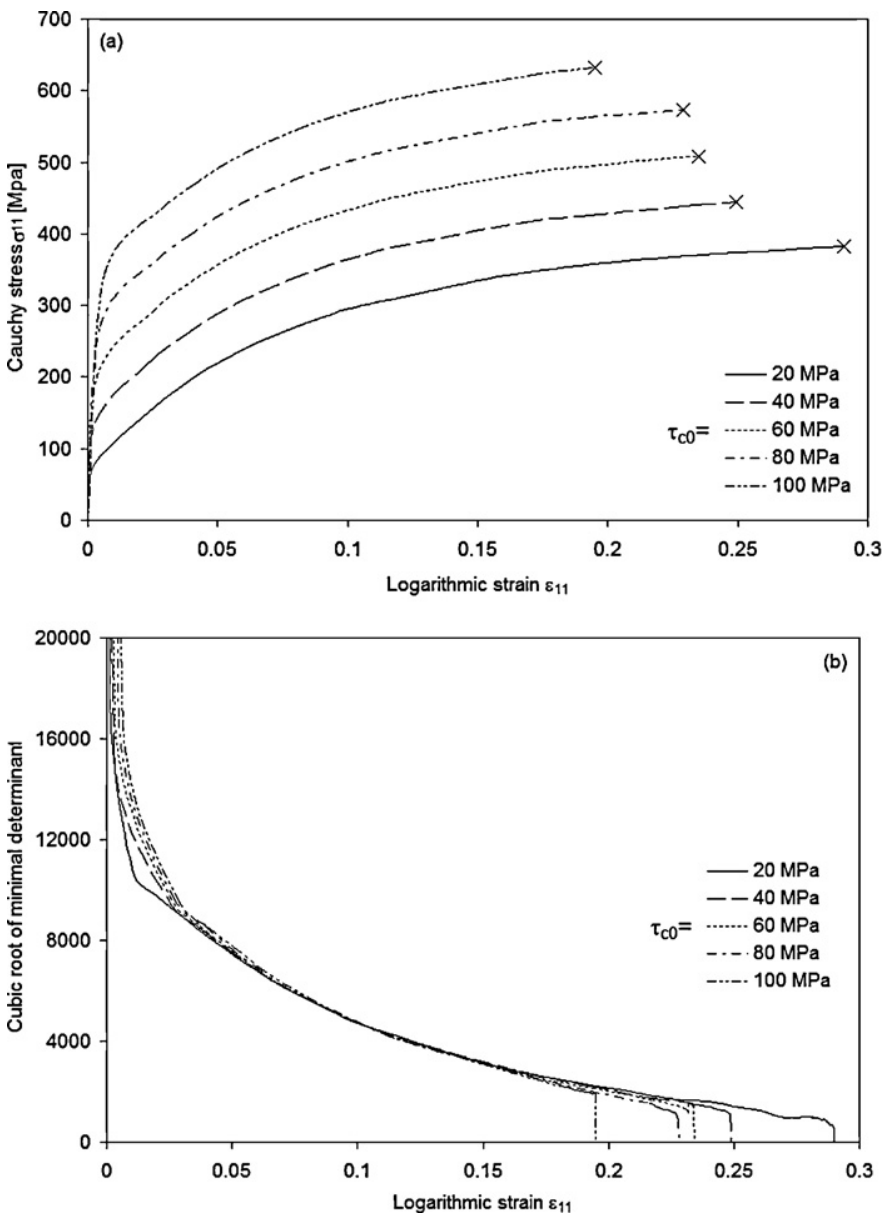

Fig. 10. Effect of the initial critical resolved shear stress $\tau_{\mathrm{c} 0}$ on the ductility limit of polycrystalline steel: (a) stress-strain behavior for plane strain tension. (b) Minimal determinant of the acoustic tensor over all orientations of the normal to the localization band. dislocation walls, and thus fewer dislocations are likely to act as obstacles to the slippage of other dislocations. This phenomenon therefore improves the ductility of the material, consistent with the observations of the previous sections (see Figs. 8b and 9b).

In the following sections, all of the material parameters reported in Table 1 are simultaneously activated.

\subsection{Impact of the initial critical resolved shear stress}

By considering different values of the initial critical resolved shear stress $\tau_{\mathrm{c} 0}$ while the remaining parameters of Table 1 are kept constant, it is clearly shown (see Fig. 10) that smaller values of $\tau_{\mathrm{c} 0}$ (or by extension for elastic limit) lead to a more ductile material. This result is consistent with the work of Luft [30], who reported that for single crystals of molybdenum, a decrease in temperature resulted in an increase in the elastic limit and thus a drop in ductility. Therefore, the effects revealed by the proposed model are in good agreement with the literature and with experimental observations.

\subsection{Impact of the volume fraction of the dislocation sheets}

As suggested by Fig. 11, an increase in the volume fraction $f$ of the dislocation walls improves ductility. This effect revealed by the model is consistent with the influence of parameter $I^{w d}$ associated with dense dislocation walls, because increasing the presence of dislocation walls has an effect that is somehow similar to increasing their intensity.
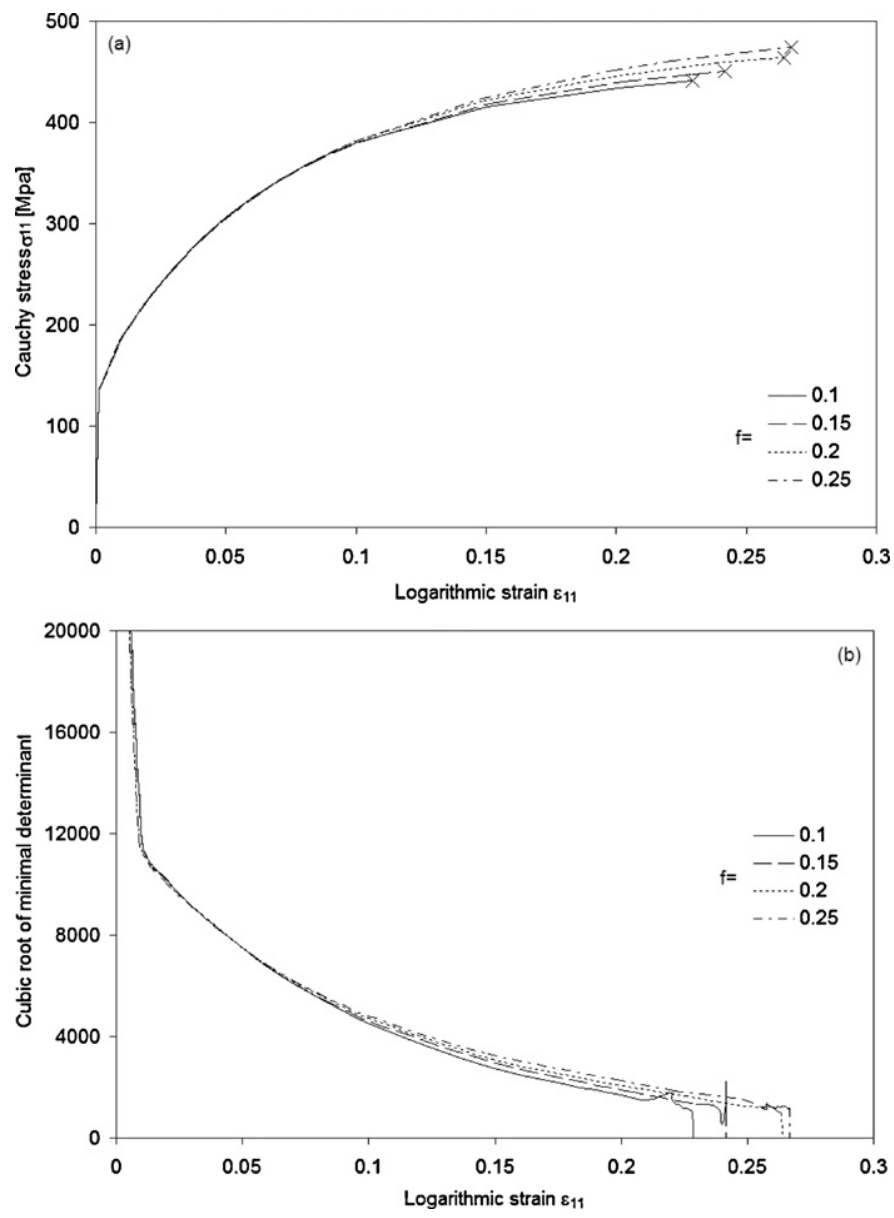

Fig. 11. Effect of the volume fraction $f$ of the dislocation sheets on the ductility limit of polycrystalline steel: (a) stress-strain behavior for plane strain tension. (b) Minimal determinant of the acoustic tensor over all orientations of the normal to the localization band. 


\section{Conclusions}

In this paper, the plastic instability criterion based on bifurcation theory first proposed by Rice has been applied to elastic-plastic tangent moduli derived from a large strain micromechanical model combined with a self-consistent scale-transition scheme. This multiscale model incorporates microscopic modeling that allows the formation and evolution of intragranular dislocation patterns on strain-paths to be precisely reproduced. To accurately describe the macroscopic behavior of polycrystalline aggregates during monotonic and complex loading paths, this approach takes into account several of their microstructural aspects, i.e., initial and induced textures, dislocation densities and softening mechanisms.

Numerical simulations have been carried out by successively selecting different subsets of material model parameters associated with specific dislocation organizations. This stepwise methodology has been adopted to clearly and separately identify the impact of each component of the intragranular substructure on the macroscopic hardening and ductility limit of single-phase steels during monotonic loading tests. The results obtained reveal trends that are quite realistic with respect to the relative ability of dislocations to move.

The resulting theoretical and numerical tool proves to be useful, as it allows the ductility of new grades of steel to be predicted at early stages of their design. Additional features of the tool are that it enables the formability of materials to be compared and it allows the impact of microstructural effects on ductility to be determined. Therefore, it could be used to optimize the ductility of new steels or to design materials with desired formability.

In future work, thorough investigations will validate the model's trends with respect to experimental data. From the experimental point of view, microstructural mechanisms corresponding to different dislocation substructures are difficult to measure and quantify. Additionally, extension of this work to strain localization analysis in the context of sequential loading paths would be of interest.

\section{References}

[1] H. Mughrabi, in Proc.: 4th Int. Conference on Continuum Models of Discrete Systems, O. Brulin, R.K.T. Hsieh (Eds.), Stockholm, 1981, pp. 241-257.

[2] D. Muller, X. Lemoine, M. Berveiller, J. Kratochvil, Solid State Phenom. 35/36 (1993) 393-398.

[3] X. Lemoine, M. Berveiller, D. Muller, Mater. Sci. Forum 157-162 (1994) 1821-1826.

[4] L. Langlois, M. Berveiller, Int. J. Plasticity 19 (2003) 599-624

[5] B. Peeters, M. Seefeldt, C. Teodosiu, S.R. Kalidindi, P. Van Houtte, E. Aernoudt, Acta Mater. 49 (2001) 1607-1619.

[6] B. Peeters, B. Bacroix, C. Teodosiu, P. Van Houtte, E. Aernoudt, Acta Mater. 49 (2001) 1621-1632.

[7] G.I. Taylor, J. Inst. Metals 62 (1938) 307-324.

[8] G. Franz, F. Abed-Meraim, T. Ben Zineb, X. Lemoine, M. Berveiller, Mater. Sci. Eng. A 517 (1-2) (2009) 300-311.

[9] G. Franz, F. Abed-Meraim, J.P. Lorrain, T. Ben Zineb, X. Lemoine, M. Berveiller, Int. J. Plasticity 25 (2009) 205-238.

[10] R.J. Asaro, J.R. Rice, J. Mech. Phys. Solids 25 (1977) 309-338.

[11] R.J. Asaro, J. Appl. Mech. 50 (1983) 921-934.

[12] D. Peirce, J. Mech. Phys. Solids 31 (1983) 133-153.

[13] D. Peirce, R.J. Asaro, A. Needleman, Acta Metall. 31 (1983) 1951-1976.

[14] T. Iwakuma, S. Nemat-Nasser, Proc. R. Soc. Lond. A 394 (1984) 87-119.

[15] J.P. Lorrain, T. Ben Zineb, F. Abed-Meraim, M. Berveiller, Int. J. Form. Process 8 (2005) 135-158.

[16] A.S. Keh, S. Weissmann, in: G. Thomas, J. Washburn (Eds.), Electron Microscopy and Strength of Crystal, 1963, pp. 231-300.

[17] F. Ronde-Oustau, B. Baudelet, Acta Metall. 25 (1977) 1523-1529.

[18] J.V. Fernandez, J.H. Schmitt, Philos. Mag. A 48 (1983) 841-870.

[19] E.V. Nesterova, B. Bacroix, C. Teodosiu, Metall. Mater. Trans. A 32 (2001) 2527-2538.

[20] E.F. Rauch, J.H. Schmitt, Mater. Sci. Eng. A 113 (1989) 441-448.

[21] E.F. Rauch, J. Mech. Behav. Mater. 4 (1992) 81-89.

[22] U.F. Kocks, J. Eng. Mater. Technol. 98 (1976) 76-85.

[23] R. Hill, J. Mech. Phys. Solids 13 (1965) 89-101.

[24] P. Lipinski, M. Berveiller, E. Reubrez, J. Morreale, Arch. Appl. Mech. 65 (1995) 291-311.

[25] J.W. Rudnicki, J.R. Rice, J. Mech. Phys. Solids 23 (1975) 371-394.

[26] J.R. Rice, in Proc.: 14th IUTAM Congress, Theorical and Applied Mechanics, W.T. Koiter (Ed.), Amsterdam, 1976, pp. 207-220.

[27] G. Franz, F. Abed-Meraim, T. Ben Zineb, X. Lemoine, M. Berveiller, Comput. Mater. Sci. 45 (2009) 768-773.

[28] S.P. Keeler, Sheet Metal Indust. 42 (1965) 683-691.

[29] G.M. Goodwin, SAE Paper No. 680093, 1968

[30] A. Luft, Prog. Mater. Sci. 35 (1991) 97-204. 